\title{
Educating our Patients about Life and the End of Life: Toward a Pedagogy of Dying
}

\author{
William Ventres, MD, MA
}

There is an extensive literature on how physicians can best educate their patients about living healthierone might call it a "pedagogy of living." In this essay, I suggest that physicians develop a "pedagogy of dying" for their adult patients: educating them about how they can approach death with some measure of grace and dignity, as consistent with their wants as possible, and cognizant of the final reality we all face. This process happens in the ambulatory settings as part of ongoing care and precedes any serious illness or the crisis of hospitalization. I draw on known models for communicating effectively, my own practice experience, and the disciplines of palliative care and bioethics in asking physicians to consider developing such a "pedagogy of dying," a kind of anticipatory guidance toward aging, infirmity, and, ultimately, death. (J Am Board Fam Med 2014;27:713-716.)

Keywords: Education, End of Life Care, Medical Ethics, Palliative Care, Physician-Patient Relations

\section{Don't smoke. \\ Eat right. \\ Use a seat belt. \\ Take your medicines regularly. \\ Exercise.}

As physicians, we make a great number of recommendations to our adult patients about how they should live. These recommendations collectively create a "pedagogy of living": suggestions for living healthier lives. What I propose here, however, is for physicians to develop a "pedagogy of dying": a way of educating patients about how to approach their deaths with some measure of grace and dignity, as consistent with their wants as possible, and cognizant of the final reality that we all face.

Much has been written-prudently and with sensitivity - about advance directives, physician orders for life-sustaining treatment, and do-not-re-

This article was externally peer reviewed.

Submitted 21 November 2013; revised 14 March 2014; accepted 2 June 2014.

From the Institute for Studies in History, Anthropology, and Archeology, University of El Salvador, San Salvador, El Salvador; and the Department of Family Medicine, Oregon Health and Science University, Portland.

Funding: none.

Conflict of interest: none declared.

Corresponding author: William Ventres, MD, MA, Urbanzación Buenos Aires III, Block H, Calle Los Maquilishuat, No. 3-A, San Salvador, El Salvador (E-mail: wventres@ gmail.com). suscitate orders, ${ }^{1-3}$ including suggestions on how to approach these issues as structural concerns embedded in the culture of medical practice., ${ }^{4,5}$ Advance care planning seeks to prepare patients and surrogates for making in-the-moment medical decisions. ${ }^{6}$ There also exist excellent guidelines for approaching patients and their families at the end of life. ${ }^{7}$ Still, most discussions about death and the desired clinical response come quite late in the course of patients' lives_-often too late for sensible dialogue to occur.

When the end of life looms inevitable and not just as an abstract awareness, a whole host of social and emotional preoccupations overwhelm patients, families, and clinicians alike. It is important for us as physicians to proactively aid patients before the end of life to ameliorate the fear, loneliness, and uncertainly that often accompanies the dying process, especially in today's fragmented medical environment. Beyond the necessity of knowing know what end-of-life interventions are desired or appropriate, we have a responsibility to help people explore and come to terms with their own mortality well before it is "their time."

There is ample space in the academic literature that describes communicative tools given to adeptly practicing a "pedagogy of living," including several models for structuring clinical conversations and the dynamics of interpersonal engagement. ${ }^{9,10}$ 
Motivational interviewing encourages the use of a stages of change model (identifying and helping along movement from precontemplation to contemplation to action and maintenance, understanding that relapse is often part of the process) that enlists patients in making behavioral change. ${ }^{11}$ Social constructivist theory submits that the "proof" of such behavioral change is in the "pudding" of the doctorpatient relationship. ${ }^{12}$ Evidence-based medicine suggests that educating patients about observed risks and benefits will help them become better decision makers. ${ }^{13}$ In addition, the idea that physicians use persuasion as a therapeutic tool to move patients toward healthier behaviors has been around for some time now. ${ }^{14,15}$

I suggest that we look beyond written declarations and advance care planning, borrow from these communicative tools, and create parallel models for a "pedagogy of dying." In context of our one-onone, relationship-centered work with our patients and their families, this would look a lot like coaching $^{16}$ : short, specific, goal-oriented discussions that assess where patients physically are in their lives, where they figuratively want to be when death comes nearer, and how to prepare for that eventuality. It would involve a clinical imagination on the physician's part, perhaps seeking known triggersthe death of a loved one, a colleague, or even a well-known personality, for example-to introduce the topic. It would engage a shared consciousness to know how to both approach and move away from the issue with sensitivity, letting patients do the work of further reflection on their own time.

To practice a "pedagogy of dying" with some semblance of skill, physicians would be well advised to consider a series of questions, which, along with organizing themes and associated tasks, are sum- marized in Table 1. First, what underlying assumptions about life and death do we bring to our encounters with patients? Thinking of death as a natural process is antithetical to the common cultural view of biomedicine, inculcated early on in medical education and training, that losing a patient is a professional, and perhaps even a personal, failure. Second, in obvious juxtaposition, what underlying assumptions about death do our patients have? How do they want to lead their lives before that event? Third, how do we best engage patients in jointly considering the topic? Given that every physician and every patient brings to the clinical encounter his or her own background and personality, it is likely that no one programmatic strategy will fit all situations when bringing up death as an integral part of life. Consciously developing a repertoire of approaches, each one flexible and responsive to patient needs in its own right, capable of unfolding in the moment or touched on again at some later time, seems prudent and wise.

Fourth, when is it time to talk about death? When is it time to listen? Undeniably, we face pressures of time, money, and other competing "desktop" interests in our work. Still, these pressures must not drive us simply to perform our roles as technical experts and neglect others we consider therapeutic witnesses who listen to stories to understand patients in context of their particular life situations and share the work of medical decision making. ${ }^{17}$ With regard to understanding individuals' perspectives on dying, much is to be gained by opening our ears, as well as our hearts, to the narratives-the individual histories, the secret fears, the successes and failures-of those in our care. Fifth, how can we move individually and collectively, with our patients, toward conceptualizing

Table 1. Developing a "Pedagogy of Dying": Key Points for Reflection

\begin{tabular}{|c|c|c|}
\hline Theme & Task & Questions to Consider \\
\hline Awareness & $\begin{array}{l}\text { Acknowledge personal and cultural } \\
\text { perspectives. }\end{array}$ & $\begin{array}{l}\text { What underlying assumptions about life and death do we bring to } \\
\text { our encounters with patients? }\end{array}$ \\
\hline Recognition & $\begin{array}{l}\text { Understand patient and family } \\
\text { perspectives. }\end{array}$ & $\begin{array}{l}\text { What underlying assumptions about death do our patients and } \\
\text { their families bring? How do they want to lead their lives } \\
\text { before that event? }\end{array}$ \\
\hline Engagement & $\begin{array}{l}\text { Develop a repertoire of } \\
\text { communicative approaches. }\end{array}$ & $\begin{array}{l}\text { How is it that we best engage patients in jointly considering the } \\
\text { topic? }\end{array}$ \\
\hline Synchronicity & $\begin{array}{l}\text { Practice "sharing" the topic with } \\
\text { patients at appropriate } \\
\text { moments. }\end{array}$ & When is it time to talk about death? When is it time to listen? \\
\hline Equilibrium & $\begin{array}{l}\text { Seek balance by recognizing } \\
\text { reality and uncovering hope. }\end{array}$ & $\begin{array}{l}\text { How can we, along with our patients, move toward } \\
\text { conceptualizing death as a normal process in a full life? }\end{array}$ \\
\hline
\end{tabular}


death as a normal process in a full life? Life is at once both a recognition of reality and an uncovering of hope; seeking for and finding a balance between the two are important undertakings at whatever arc in its cycle.

Over the years in my own community-based family practice I have been mostly successful attending to such a "pedagogy of dying": helping people in the recognition that we as human beings are of a nature to die and that self-reflection in the context of one's mortality is neither irrelevant nor absurd. With patients in whom I appreciate some ability to seek meaning in both life and death (and not all patients seem to fit this bill), I use coaching skills and borrow from the various models of communication as necessary and helpful. The biopsychosocial approach, combined with a "probe and pause" style, is my conceptual companion as I explore what death represents from my patients' perspectives. The power of my healing relationships with patients is a key component in these interactions: my intent is to convey to them the expectation that, in health and in sickness, my colleagues and I will be there as we are able. Most important, I try to listen deeply and with sincerity, knowing that each one of my patients inevitably thinks and acts differently than I do.

There are times I have failed in my efforts to address what-along with taxes-is a certainty we all must face. I fall short with some patients, not primarily because they are resistant, in denial, or just not ready, although plenty of patients and families fit these criteria. I fall short because I do not hear them. Even as a relatively reflective medical practitioner, I still see and attend to different realities and perceived needs than do my patients, and I am on occasion not able to acknowledge these differences. Fortunately, I am apparently in good company, for it seems physicians commonly do poorly in making this kind of distinction. ${ }^{18}$ The vast majority of my shortcomings in this regard have not been irreparable. Given a foundation of trust, respect, and even perhaps faith, ${ }^{19}$ it is not always what one does that is most important when awkward communications occur. It is what one does next: honest disclosure and recognition of personal limitations play important roles when discussing sensitive topics in medical practice. My discussions with patients are part of a healing process that occurs over time. As patients' positions in the contour of their lives change, so too does their willingness to touch on issues once best left alone.

The disciplines of palliative medicine and biomedical ethics have embraced the acknowledgment and practice of sensitive care in end-of-life situations. ${ }^{20}$ Their use of multidisciplinary teams to bear witness to and accompany patients and their families through the dying process (as well as to assist in resolving conflicts in management plans at the end of life) has proved extremely valuable. Yet a "pedagogy of dying" precedes both the onset of severe illness and the crisis of hospitalization. It happens in clinic settings, bit by bit, fit into in visits short or long, simple or complex, addressed as part of ongoing care. It happens as a natural part of the give and take of clinical interactions, subtly yet consciously. It is a discovery by practitioners and patients alike that, for most, human mortality is a normal life event to be prepared for expectantly and attentively, with thoughtfulness and care.

When at my best, what I hope I provide, and suggest other clinicians consider providing, is a kind of anticipatory guidance toward aging, infirmity, and ultimately death. By offering that guidance, we as medical professionals can appreciate and nurture the richness of our shared presence with patients. We can help our patients live their lives, at whatever stage, a bit more free from emotional angst and suffering than they might otherwise live them. At the same time we realize these therapeutic aspirations, through a "pedagogy of dying" we can begin to move the culture of medicine toward a more humane and dignified appreciation of death as part and parcel of a full life, well lived.

The author thanks Michael Fetters, MD, MPH, MA, for his thoughtful comments on this article.

\section{References}

1. Tulsky JA. Beyond advance directives: importance of communication skills at the end of life. JAMA 2005; 294:359-65.

2. Bomba PA, Kemp M, Black JS. POLST: an improvement over traditional advance directives. Cleve Clin J Med 2012;79:457-64.

3. Lamas D, Rosenbaum L. Freedom from the tyranny of choice-teaching the end of life conversation. N Engl J Med 2012;366:1655-7.

4. Lynn J, Forlini JH. "Serious and complex illness" in quality improvement and policy reform for end-oflife care. J Gen Intern Med 2001;16:315-9. 
5. Yuen JK, Reid, MC, Fetters, MD. Hospital do-notresuscitate orders: why they have failed and how to fix them. J Gen Intern Med 2011;26:791-7.

6. Sudore RL, Fried TR. Redefining the "planning" in advance care planning: preparing for end-of-life decision making. Ann Intern Med 2010;153:256-61.

7. Sulmasy DP. A biopsychosocial-spiritual model for the care of patients at the end of life. Gerontologist 2002;42(Spec No 3):24-33.

8. Street RL, Makoul, G, Neeraj KA, Epstein RM. How does communication heal? Pathways linking clinician-patient communication to health outcomes. Patient Educ Couns 2009;74:295-301.

9. Stewart M, Brown JB, Weston WW, McWhinney IR, McWilliam CL, Freeman TR. Patient-centered medicine: transforming the clinical method. Thousand Oaks, CA: Sage Publishers; 1995.

10. Frankel RM, Stein T. Getting the most out of the clinical encounter: the Four Habits model. Perm J 1999;3:79-88.

11. Rollnick S, Butler CC, Kinnersley P, Gregory J, Mash B. Motivational interviewing. BMJ 2010;340: c1900.

12. Wilson HJ. The myth of objectivity: is medicine moving toward a social constructivist medical paradigm? Fam Pract 2000;17:203-9.
13. Haynes RB, Devereaux PJ, Guyatt GH. Clinical expertise in the era of evidence-based medicine and patient choice. ACP J Club 2002;136:A11-4.

14. Cameron KA. A practitioner's guide to persuasion: an overview of 15 selected persuasion theories, models and frameworks. Patient Educ Couns 2009;74: 309-17.

15. Frank JD. Persuasion and healing: a comparative study of psychotherapy. Revised ed. New York: Schocken Books; 1974.

16. American College of Preventive Medicine. Coaching and counseling patients. Available from: http://c.ymcdn. com/sites/www.acpm.org/resource/resmgr/timetoolsfiles/coachingclinicalreference.pdf. Accessed November 15, 2013.

17. Herbert CP. Stories in family medicine commentary: the power of stories. Can Fam Physician 2013; 59:62-5.

18. Stonington S. The debt of life-Thai lessons on a process-oriented ethical logic. N Engl J Med 2013; 369:1583-5.

19. Ventres $W$, Dharamsi S. Beyond religion and spirituality: faith in the study and practice of medicine. Perspect Biol Med 2013;56:352-61.

20. Carter BS, Wocial LD. Ethics and palliative care: which consultant and when? Am J Hosp Palliat Care 2012;29:146-50. 